\title{
Integrated approach to drilling and completing a multistage well
}

Author: Stuart Wilson

Multistage Stimulation (MSS) has often been viewed as simply running a completion string followed by pumping services. However; the early attempts at uncemented, openhole multistage stimulation completions in the Middle East were met with mixed operational success. It became clear that the standard completion approach and stimulation procedures could not be directly applied. A new set of best practices would be required in these Middle East wells that included a new and integrated, multidisciplinary approach that took a step backwards in the process to the pre-drilling phase, focusing on well planning optimization to maximize the multistage completion technique and ultimately the well productivity.

Almost all the horizontal wellbores in the carbonate formations where MSS assemblies were deployed were drilled in the direction of maximum or principal in-situ stress $\left(\sigma_{\max }\right)$. The key challenge therefore was to modify the well planning strategy to drill wells in the direction of minimum horizontal in-situ stress $\left(\sigma_{\mathrm{min}}\right)$ to generate multiple transverse fractures. Drilling perpendicular to $\sigma_{\min }$ is more challenging and requires careful consideration of mud weights to minimize formation break-out or break-down. Likewise, deploying MSS systems in these wells is challenging since there are often fewer locations to place open-hole packers due to potential borehole instability.

This presentation will go through some of the lessons learned in forming the new integrated approach and applied guidelines. The successful implementation of these ideas resulted in outstanding production. 